\title{
Peso de la ley y eficacia directa de la Constitución: evolución del sistema de fuentes formales en la República de Chile
}

\author{
Weight of the Law and Direct Effectiveness \\ of the Constitution: Evolution of the Formal \\ Source System in the Republic of Chile
}

Peso da lei e eficácia direta da Constituição: evolução do sistema de fontes formais na República do Chile

Julio César Rojas Chamaca*

* https://orcid.org/0000-0001-7269-6973. Universidad San Sebastián, sede Santiago, Chile. julio.rojas@uss.cl

DOI: 10.5294/dika.2020.29.1.6 


\section{Resumen}

El objetivo del presente trabajo es identificar, a través de un estudio descriptivo, analítico y crítico, dos momentos en el ordenamiento nacional. El primero de ellos, referido al valor que tuvo la ley en el desarrollo y la institucionalización de la República de Chile, cuya cultura jurídica se desarrolló al amparo del principio de legalidad, que poseía un reconocimiento creciente derivado de su valor democrático, lo que implicó un desplazamiento de otras fuentes en el ordenamiento. El segundo momento tiene relación con la existencia de un nuevo paradigma, el del Estado constitucional y democrático de derecho, progresivamente consolidado a partir de la segunda mitad del siglo XX y cuya premisa es la fuerza normativa y eficacia directa de la constitución por los órganos del Estado y, en particular, los tribunales de la República. La hipótesis de esta investigación refiere que aun cuando es posible constatar una evolución en el sistema de fuentes, el principio de legalidad está arraigado en la cultura jurídica chilena. En tal dimensión, la prevalencia de las disposiciones de la Constitución por sobre la ley debe resaltar la necesidad de que, en caso de existir un conflicto que requiera la intervención de un tribunal, se debe intensificar el respeto por la bilateralidad de la audiencia como garantía para reducir la discrecionalidad judicial.

\section{Palabras clave}

Principio de legalidad; orden portaliano; sistema de fuentes formales; Estado constitucional de derecho; evolución del sistema de fuentes en Chile. 


\section{Abstract}

This article intends to identify, through a descriptive, analytical, and critical study, two moments in the national legal system. The first one refers to the role that the law played in the development and institutionalization of the Republic of Chile, whose legal culture was created under the principle of legality. The increasing recognition of this principle derived from its democratic value, which involved the superseding of other sources in the legal system. The second moment is related to the existence of a new paradigm: the constitutional and democratic state of law. It has progressively consolidated since the second half of the 20th century and its premise is the regulatory force and direct effectiveness of the Constitution under governmental agencies, particularly the courts of the Republic. The hypothesis of this research is that, even though there has been an evolution in the source system, the principle of legality is rooted in the Chilean legal culture. So, the prevalence of constitutional provisions over the law should highlight the need to intensify, in case of a conflict that requires the intervention of a court, the respect for the duality of parties in a legal proceeding as a guarantee for reducing judicial discretion.

\section{Keywords}

Principle of legality; Portalean order; formal source system; constitutional state of law; evolution of the source system; Chile. 


\section{Resumo}

O objetivo deste trabalho é identificar, por meio de um estudo descritivo, analítico e crítico, dois momentos no ordenamento nacional. O primeiro deles refere-se ao valor que a lei teve no desenvolvimento e institucionalização da República do Chile, cuja cultura jurídica foi desenvolvida sob o princípio da legalidade, que teve um crescente reconhecimento derivado de seu valor democrático, o que implicou um deslocamento de outras fontes no ordenamento. $\mathrm{O}$ segundo momento está relacionado à existência de um novo paradigma, o do Estado constitucional e democrático de direito, progressivamente consolidado a partir da segunda metade do século XX e cuja premissa é a força normativa e a eficácia direta da Constituição pelos órgãos do Estado e, em particular, dos tribunais da República. Levanta-se a hipótese de que, embora seja possível verificar uma evolução no sistema de fontes, o princípio da legalidade está enraizado na cultura jurídica chilena. Nesse sentido, a prevalência das disposições da Constituição acima da lei deve realçar a necessidade de que, caso exista um conflito que exija a intervenção de um tribunal, o respeito à bilateralidade da audiência deve ser intensificado como garantia de reduzir a discricionariedade judicial.

\section{Palavras-chave}

Princípio da legalidade; ordem portaliana; sistema de fontes formais; Estado constitucional de direito; evolução do sistema de fontes; Chile. 
Sumario: Introducción. 1. El peso o el valor de la ley en el siglo XIX. 2. La eficacia directa de la Constitución. Reflexiones finales

\section{Introducción}

En este artículo se analizarán dos momentos en la cultura jurídica de Chile: el primero corresponde al peso de la norma o el valor que a la ley se le asignó para proveer de orden a la República. En esa línea, es preciso recordar que durante un largo periodo -que comenzó con la independencia-se supuso que la ley era la disposición normativa más importante. Esta afirmación se funda en que su creación y puesta en vigor en el ordenamiento jurídico es una característica del soberano, ${ }^{1}$ que era la nueva República. Sobre la prevalencia de la ley como fuente, se explica: "El culto a la ley como declaración de voluntad, implicó el culto al emisor de dicha voluntad y este elemento permanece vigente en nuestro sistema jurídico mucho tiempo después de la desaparición de la escuela de la exégesis". ${ }^{2}$

El segundo momento corresponde a la constatación de la superación de la ley porque el parámetro constitucional ha adquirido un protagonismo nuevo. En efecto, la constitución ha adquirido fuerza normativa que irradia a todo el sistema jurídico, lo que se comprueba, entre otros ejemplos, por la existencia de controles de constitucionalidad de las leyes o el ejercicio de acciones de las personas para resguardar derechos fundamentales ante los tribunales de la República; lo anterior ha significado el desplazamiento progresivo de las leyes a un segundo plano, por lo que hoy la validez de la ley -a priori-genera incertidumbre.

La legalidad, en sentido amplio, definió un rasgo de la nación y ha proveído de un sentido histórico a la República de Chile. En efecto, la ausencia de tradición y de cultura cívica de la joven nación determinó que la élite gobernante erigiera a la ley como herramienta de legitimidad y desarrollo, al mismo tiempo que se estimó en consonancia con las ideas portalianas "que las leyes eran eficaces para hacer virtuosos y felices a los pueblos". ${ }^{3}$ En perspectiva, si se entiende a la institucionalización como un proceso a través del cual las organizaciones y los procedimientos adquieren valor y estabilidad definida, es posible afirmar que el sentido de regularidad jurídica plasmado en la existencia de leyes, producidas y desarrolladas por la clase gobernante en las primeras décadas de vida independiente de la República de Chile, contribuyó a la consolidación de la nación.

1 En dicha línea se afirma: “Ley y soberano son pues algo así como las dos caras de una misma moneda, la cara que refleja el poder supremo es el soberano, la que refleja el derecho de superior jerarquía es la ley" (Francisco J. Laporta, El imperio de la ley. Una visión actual, Madrid, Trotta, 2007, p. 153).

2 Carlos Amunátegui, Teoría y fuentes del Derecho: Boni et Aequi, Santiago, Ediciones Universidad Católica de Chile, 2016, p. 64.

3 Julio Heise, 150 años de evolución institucional, 7 ed., Santiago, Editorial Andrés Bello, 1990, p. 27. 
Lo que se pretende analizar en este trabajo es que, en Chile, desde su independencia y en especial desde la Constitución de 1833, como en los años siguientes, comenzó un proceso continuo de sustitución de leyes del régimen anterior, de sistematización de cuerpos legales a través de la codificación, de reformulación de las instituciones existentes, para legitimar y dar estabilidad a los gobiernos a través de nuevos órganos. Es posible identificar cierta coherencia en la élite chilena sobre la idea que se expone, lo que se evidencia como un elemento válido al hablar de institucionalización en la nación. Dicho fenómeno se observa a través de un proceso legislativo que terminó en una especie de deificación de la ley como fuente prevalente del derecho, lo que en opinión de los historiadores es una consecuencia del régimen portaliano. ${ }^{4}$ Sobre el particular, dice Encina:

Durante los sesenta años que duró la tradición portaliana se mantuvieron con rara porfía los basamentos de un ideario, verdadera fe laica, expresado en el patriotismo, la abnegación cívica, la honradez, la justicia, el respeto inflexible en las leyes y la seriedad y decencia en todos los actos públicos y privados. ${ }^{5}$

¿Contribuye la ley al orden que da sentido a la República? Pese al escepticismo de Portales ${ }^{6}$ hacia la ley ¿puede sostenerse que el proceso de organización estatal, a través de las leyes y sus derivados, atemperó los personalismos, las conflagraciones internas por un tiempo considerable en el siglo XIX y ordenó las relaciones de la comunidad por medio de la codificación? ¿Es posible sostener que la ley posee legitimidad en la actualidad? ¿Qué pensaría un erudito como Andrés Bello del principio de supremacía constitucional y de la infravaloración de la ley que es un fenómeno sostenido a partir de la segunda mitad del siglo XX? ¿Posee auctoritas la ley en un ordenamiento donde la fuente primordial es la Constitución?

Con la finalidad de aproximar respuestas a las preguntas planteadas, el objetivo de este trabajo es analizar, a través de un estudio descriptivo y crítico, dos momentos de la cultura jurídica chilena. El primero de ellos, referido al valor que la ley tuvo en el desarrollo e institucionalización de la República, con independencia de las fundadas objeciones que se puedan formular sobre

$4 \quad$ Diego Portales (1793-1837). Comerciante y ministro de Estado durante el gobierno de Joaquín Prieto (17861854), encabezó el bloque conservador que enfrentó a las fuerzas liberales en la guerra civil librada entre 1829 y 1830. Representa una figura gravitante para toda la producción historiográfica del siglo XIX y se le atribuye un rol protagónico en la articulación política de la República de Chile. Su importancia y valoración, así como también la significación efectiva y real de su obra política, y de su herencia, sigue siendo hasta hoy materia de una interminable discusión (Katya Araújo y Nelson Beyer, "Autoridad y autoritarismo en Chile. Reflexiones en torno al ideal-tipo portaliano", en Revista Atenea 508 (2013), pp. 171-185, en http://dx.doi.org/10.4067/S071804622013000200012, fecha de consulta: 4 de mayo de 2019.

5 Francisco Encina, Resumen de la Historia de Chile, 9 ed., t. II, Santiago, Editorial Zigzag, 1972, p. 832.

6 Se refuerza -en opinión de Alfredo Jocelyn-Holt- la desconfianza de Portales a las leyes y a toda pretensión racionalista, al citar una carta del ministro que dice: "en Chile la ley no sirve para otra cosa que no sea producir anarquía, la ausencia de sanción, el libertinaje, el pleito eterno, el compadrazgo y la amistad... la ley la hace uno procediendo con honradez y sin espíritu de favor" (Alfredo Jocelyn-Holt, El peso de la noche. Nuestra frágil fortaleza histórica, Buenos Aires, Ariel, 1997 p. 86). 
su validez sustancial. Sin embargo, el valor portaliano de la ley, vigente desde el siglo XIX, conocido también como "Estado legal de derecho", es reemplazado sistemáticamente desde mediados del siglo XX por otro, denominado "Estado constitucional de derecho", que se caracteriza por la fuerza normativa de la constitución y su eficacia directa, con la consiguiente aplicación y obligatoriedad para todos los órganos y sujetos que conviven en el Estado. Se evidencia una evolución en el sistema de fuentes del derecho que se traduce en una progresiva superación del valor tradicional e histórico de la ley, que transforma la constitución en la fuente preferente del ordenamiento.

Sin perjuicio de la afirmación realizada, la hipótesis de esta investigación refiere que aun cuando es posible constatar una evolución en el sistema de fuentes, el principio de legalidad está arraigado en la cultura jurídica chilena. En tal dimensión, la prevalencia de las disposiciones de la Constitución por sobre la ley debe resaltar la necesidad de que, en caso de existir un conflicto que requiera la intervención de un tribunal, se debe intensificar el respeto a la bilateralidad de la audiencia como garantía para reducir la discrecionalidad judicial.

\section{El peso o el valor de la ley en el siglo XIX}

La influencia española en América es natural, "porque 300 años de dominación han dejado huellas profundas en nuestro modo de entender y aplicar el derecho". ${ }^{7}$ Sin embargo, y pese a que Chile adquirió su independencia en 1818, las leyes antiguas -aquellas que regían las relaciones jurídicas comunes como las procesales referidas a la tutela de derechos por tribunales- fueron aplicadas con posterioridad por los órganos de la nueva República. No existe una ruptura radical del sistema nuevo con el régimen anterior. ${ }^{8}$ La independencia surge como un hecho político inédito que genera problemas a la clase dirigente en torno al poder. No obstante, el orden social, económico y jurídico permanece esencialmente inalterado, solo que ahora debía ser administrado por funcionarios que no respondían a las directrices de los Borbones.

Desde el punto de vista de la aplicación del derecho español en los conflictos con posterioridad a la independencia de Chile, es posible consignar el siguiente caso resuelto por un tribunal de Valparaíso:

En diciembre de 1855 se condenó a José Arias a que respondiese por los daños de un incendio que había causado. Para fundamentar su sentencia, el juez le solicitó

$7 \quad$ Jorge Baraona, “La cultura jurídica chilena: apuntes históricos, tendencias y desafíos”, en Revista de Derecho P. Universidad Católica de Valparaíso XXXV (2010), p. 429.

8 Esta afirmación es compartida por la doctrina. En tal sentido se afirma: “En Chile, la revolución independentista, efectivamente modificó todo el sistema de gobierno nacional, aunque el derecho privado continuó rigiéndose por el derecho castellano-indiano vigente antes de 1810. Incluso la Novísima Recopilación de Leyes de España entró a regir al país sin que ella hubiese sido jamás aprobada para América, ni por las autoridades españolas, ni por las autoridades revolucionarias" (Amunátegui, Teoría y fuentes del Derecho: Boni et Aequi, op. cit., p. 45). 
a la Corte Suprema que se pronunciase al respecto, y por medio de una sentencia fechada el 2 de enero de 1856, la Corte condenó a Arias por el delito de incendio basándose en la Ley $1^{\text {a }}$ del título II del libro $8^{\circ}$ del Liber Iudiciorum o Libro de los Jueces, un cuerpo de leyes visigodo, de carácter territorial, dispuesto por el rey Recesvinto y publicado en el año 654, que a su vez encontraba fundamento en el Código de Eurico, que data del año 480 de la era cristiana. ${ }^{9}$

En forma adicional, cabe señalar que los textos de derecho sustantivo o procedimental de la joven República aún utilizan como referencias a textos españoles de la Edad Media. En 1881, el profesor José Bernardo Lira, en la tercera edición de su obra Prontuario de los juicios o Tratado de procedimientos judiciales $i$ administrativos con arreglo a la lejislación chilena, "recurre de manera regular a las Siete Partidas, en particular a la Séptima, y a la Novísima Recopilación para ir determinando las normas aplicables al procedimiento criminal". ${ }^{10} \mathrm{La}$ aplicación del derecho del antiguo régimen no es un hecho aislado, sino que es una situación sistemática por los tribunales. ${ }^{11}$

Se puede observar que, a la luz de lo expuesto, era necesario reemplazar los cuerpos legales de la Colonia en forma progresiva para la legitimación del nuevo régimen. El orden portaliano advertía tal circunstancia, y pese a que fue autoritario en lo político, se abrió y liberalizó la economía, además de permitir el desarrollo de la cultura, ambos entendidos como elementos constitutivos de la incipiente identidad nacional. Dentro de aquel ámbito de desarrollo, se contemplaba la inclusión de un nuevo sistema jurídico, que implicó el surgimiento de nuevas leyes.

En la generación de la leyes se tuvo la visión e influencias filosóficas y jurídicas de la época; en tal sentido, y como lo expresa Baraona, ${ }^{12}$ se pueden señalar las siguientes:

(a) De la España Borbónica, la ilustración, que en materia jurídica buscó la nacionalización de la norma, a la búsqueda de la primacía de lo legal, produciéndose un repliegue del derecho común y una preeminencia del derecho legislado. Una consecuencia relevante fue la creación de los primeros estudios de Derecho en Chile, con la fundación de la Universidad de San Felipe.

9 Cristóbal García-Huidobro, Yo, Montt, Santiago, Editorial Vergara, 2009, p.134.

10 Eric Palma, La constitucionalización del proceso penal en Chile y sus alcances en la doctrina y práctica procesal del siglo XIX, Colección de Investigaciones Jurídicas, Santiago, Universidad Alberto Hurtado, 2004, p. 31.

11 En una investigación realizada por Eric Palma sobre la práctica judicial de la localidad de Curepto, Región del Maule, Chile, a fines del siglo XIX y principios del XX identifica la aplicación del derecho español del antiguo régimen: a) sentencia absolutoria de 3 de enero de 1901 respecto de Juan de Dios Castillo, el juez invoca el Código Penal chileno y Leyes 26, Título $1^{\circ}$ partida $7^{a}$, I 12 título 14 partida $3^{3}$; b) los apoderados de dos acusados absueltos por el delito de homicidio; fundó su defensa no solo en el Código Penal chileno, sino también en las Siete Partidas. Palma confirma que "no cabe duda que las Siete Partidas son citadas como cuerpo legal vigente. Ellas contribuyen a justificar el fallo y son invocadas como norma de dicho rango y no como doctrina jurídica. En su momento ni el fiscal del tribunal, ni el de la Corte, menos aún la propia Corte de Apelaciones, hicieron cuestión alguna por la cita del texto de Alfonso X. La sentencia fue confirmada en todas sus partes" (Palma, La constitucionalización del proceso penal en Chile y sus alcances en la doctrina y práctica procesal del siglo XIX, op. cit., pp. 43-50).

12 Baraona, “La cultura jurídica chilena: apuntes históricos, tendencias y desafíos”, op. cit., pp. 430-437. 
(b) De Francia, la doctrina iusracionalista, que se tradujo en un "culto a la ley y la fe en su virtud propia". ${ }^{13}$

Su efecto más conocido fue el proceso codificador de las leyes, que se plasmó en el Código Civil. La codificación tuvo un impacto profundo en Occidente, y sin duda en Chile, campo fértil para legitimar a la República y consolidar el régimen vigente. En opinión de Guzmán Brito, el Código Civil chileno es "la obra legislativa mejor lograda del siglo XIX, superior a todas las de su época, incluyendo al gran Código Civil francés" ${ }^{14}$ En efecto, Andrés Bello, en su erudición, armonizó la influencia del Code Civil, con el derecho común y castellano; es calificado como un codificador moderado, ${ }^{15}$ no rompió de forma íntegra con el sistema jurídico anterior, sin embargo, recepcionó el derecho francés, algunos otros códigos modernos y las influencias liberales de su época con lo existente.

La influencia francesa de la época de la codificación tuvo un espacio fecundo en la joven República ya que mezcló lo jurídico y político: afianzar la identidad nacional por cuerpos legales propios no necesariamente tuvo como fin romper de manera expresa con el sistema anterior. Aquella afirmación es posible confirmarla si se analiza el concepto de ley del artículo 1 del Código Civil chileno que dice: "es una declaración de la voluntad soberana", lo que transmitió Andrés Bello fue que la ley, al emanar de la soberanía, "consiste en la independencia de la nación; esto es, que no recibe leyes de otra". ${ }^{16}$ No obstante, y pese que adscribía ideales libertarios, la estrategia de Bello, como se ha adelantado, no tuvo en lo jurídico un criterio revisionista o revolucionario: "Bello 'institucionaliza' prácticas y costumbres; las provee de una legitimidad actual, normativa y textual. En el fondo, regula más que restaura; reorienta, le da un sustento racional a lo que hasta hora obliga por tradición o simple inercia". ${ }^{17}$

De lo expuesto ¿qué es lo relevante para este estudio? La aplicación del Código Civil y la recepción de la codificación en Chile significó una cierta intensificación legalista en la manera de concebir y aplicar el derecho que perdura en el sistema jurídico chileno hasta bien avanzado el siglo XX. Una cualidad de la Escuela de la Exégesis era que llamaba a los juristas y jueces entender las normas en clave de plenitud, en virtud de ello, la ley se reconoce como principal

14 Alejandro Guzmán Brito, “La codificación del Derecho", en Revista Derecho P. Universidad Católica de Valparaíso 8 (1984), p. 12.

15 La moderación de Bello se constata en el sentido de que con la codificación de las leyes en Chile "no se pretende crear nada nuevo, lo que implica que el rechazo a la legislación y al derecho vigente es de tipo formal, se rechaza y critica el desorden y la multiplicidad de textos, lo farragoso de su estilo, el exceso de comentaristas más que su estilo" (María Angélica Figueroa, "La codificación civil chilena y la estructuración de un sistema jurídico legalista", en AA.VV., Homenaje a don Andrés Bello, Santiago, Editorial Jurídica de Chile, 1982, p. 382).

16 Amunátegui, Teoría y fuentes del derecho: Boni et Aequi, op. cit., p. 55.

17 Jocelyn-Holt, El peso de la noche. Nuestra frágil fortaleza histórica, op. cit., p. 251. 
y fundamental expresión de la voluntad general, y, por tanto, la función del juez era aplicar de manera irrestricta dicho mandato. El juez no posee, en este modelo, un ámbito de discrecionalidad.

Sin perjuicio de que la codificación y la Escuela de la Exégesis surgieron en Francia, es necesario remarcar que su filosofía fue superada con nuevas escuelas ${ }^{18}$ que llamaron a una interpretación más abierta de las leyes. Con todo, en Chile, tales tendencias no impactaron de manera sustantiva en la forma de aplicar e interpretar el derecho y la ley. Es posible sistematizar algunos de los efectos de la Escuela de la Exégesis en la cultura jurídica nacional: i) reducción en el sistema de fuentes; ${ }^{19}$ ii) interpretación rígida, apegada a la letra de la ley; iii) prevalencia de la seguridad jurídica por sobre la aplicación de criterios de justicia material; iv) la intangibilidad de la fuente legislativa fue tutelada posteriormente por el surgimiento del recurso de casación en el fondo, que garantiza el predominio de la ley sobre la sentencia.

En dicha perspectiva, un aspecto no previsto por el modelo que adscribe a la Escuela de la Exégesis refiere que la norma como objeto de la ciencia del derecho es una abstracción, que se diferencia de lo fáctico $\mathrm{y}$, por ende, debe ser interpretada. Con acierto, sobre la norma jurídica se dice que es, "en definitiva, la abstracción de una posibilidad, que puede o no ocurrir en el plano de lo real concreto y que en su realización efectiva, es totalmente independiente de la abstracción en sí misma". ${ }^{20}$

Lo anterior supone que, en caso de existir un conflicto intersubjetivo de intereses entre partes, y llevado el asunto a un tribunal para que dirima, será necesario que el tercero (juez) realice una actividad de interpretación de la norma abstracta al caso particular, ello permite afirmar que la aplicación de la ley nunca

18 En Alemania nace la Escuela Histórica del Derecho, fundada en 1815 por Savigny, Eichorn y Goschen; esta escuela valorizaba el derecho consuetudinario y la importancia de la continuidad histórica en la formación del derecho y fue crítica de la codificación napoleónica. En Francia, se destaca a François Gény, quien en 1899 impulsó la Escuela Científica, esta sostiene que frente a vacíos en la ley, los intérpretes buscan la solución partiendo de la idea de justicia y de la naturaleza real de las cosas. La interpretación es libre porque no está sometida a la autoridad positiva de la fuente formal. Es científica porque se apoya en los elementos objetivos que solo las ciencias pueden proporcionar (Ducci, Interpretación jurídica, op. cit., pp. 24-28).

También destaca la Escuela del Derecho Libre que se relaciona con la obra del profesor de Friburgo Herman Kantorowicz: "la lucha por la ciencia del derecho" de principios del siglo XX; su tesis se resume en: a) el derecho no es solo estatal: es libre y vivo; b) la ley es incapaz de dar respuesta a todos los casos posibles (no existe el dogma de la plenitud del ordenamiento jurídico); c) primacía de la equidad y de la justicia o prescindencia del juez hacia la ley; d) libre descubrimiento del derecho; e) no hay más garantía de justicia que la personalidad del juez (José Ignacio Núñez, Neoconstitucionalismo y control de constitucionalidad de la ley. ¿El constitucionalismo del derecho libre?, México, Porrúa, 2013, pp. 13-37).

19 La reducción en el sistema de fuentes generada por la codificación y el método de la exégesis contrasta con la amplitud y diversidad de fuentes en el derecho romano. En tal sentido, Ducci explica que la "interpretación fue, en el fondo, la gran fuerza creadora del derecho romano y los magistrados participaron en gran medida en la formación del derecho. El derecho honorario y, sobre todo, el pretoriano, extendiendo, corrigiendo y supliendo la costumbre y la ley, llegó a ser la fuente más fecunda y mejor adaptada al derecho de Roma" (Ducci, Interpretación jurídica, op. cit., pp. 17-20).

20 Ariel Álvarez, Derecho y realidad. Notas de teoría sociológica, Rosario, Editorial Juris, 2005, p. 142. 
será mecánica. Ese es el error de la Escuela de la Exégesis: prescinde de los hechos, de lo fáctico y se apoya solo en una base frágil de textos.

En la realidad, las leyes suelen dejar intersticios que fuerzan al juez a interpretar para adjudicar derechos en disputa. Pueden ser más o menos precisas, es decir, pueden determinar con mayor o menor claridad los cursos de acción por seguir. Es deseable que las leyes sean lo suficientemente definidas para poder ordenar la conducta de las personas, tanto particulares como agentes del Estado, a fin de entregar un marco de certeza y predictibilidad en las relaciones humanas. De esta forma, se contribuye a una relación entre gobernantes y gobernados en la que los segundos no son meramente administrados o conducidos según el capricho de la autoridad, sino que están sometidos al gobierno de las leyes generales y predecibles, lo que favorece el despliegue de su libertad y la capacidad de asumir proyectos complejos de largo aliento.

Para lograr este objetivo, el cuerpo de leyes debe satisfacer ciertas condiciones que le permitan orientar la conducta humana, como su generalidad, coherencia, estabilidad y vigencia pro futuro, así como su prohibición de retroactividad, entre otras.

El legislador, cuando dicta normas generales, debe esforzarse para que las leyes cumplan estas exigencias, y debe ser todo lo claro y preciso que el asunto permita.

Los jueces, por su parte, tienen en la actualidad una gran responsabilidad en preservar las exigencias del Estado de derecho. Así, junto con el reconocimiento del inevitable margen de interpretación de los jueces, habría que reconocer que su labor hermenéutica puede tanto realizar dichas exigencias como apartarse de ellas. Existen diversas técnicas asociadas a una buena judicatura que apuntan a lo primero. Ejemplo de ellas son: i) una actitud del juez de sujetarse al derecho mirando al pasado (al derecho validado y vigente en la comunidad) en vez de al futuro (a cómo le gustaría que fuere la comunidad y su derecho); ii) garantizar el deber de fundamentación de las sentencias, argumentando con precisión sus fallos, dando razón de los principios que explican su actuar, y siendo consistente con ellos en casos futuros; iii) asegurar la debida congruencia entre lo pedido y lo efectivamente resuelto con abstracción de sus preconceptos modelizantes de la sociedad; iv) una conciencia de las limitaciones de la judicatura, que no tiene las capacidades institucionales para procesar evidencia empírica ni resolver materias técnicas, ni para abordar asuntos puramente políticos de forma legítima.

Del contexto de lo referido es posible observar que el peso o el valor de la ley en el siglo XIX confiere un sentido histórico a la República de Chile. Ella se crea deliberadamente por la voluntad soberana, a través de los órganos que la representan. De esa manera, es posible considerar que la ley definió al poder y fue la forma de la élite gobernante para legitimar las acciones de los gobier- 
nos a partir de 1830 en Chile. Luego de la independencia, la historia fue de conflicto permanente, era preciso superar dicha violencia, y una herramienta para lograr tales fines fue la ley. A través de ella se entregaban patrones de conducta, esto facilitó la institucionalización y generó un orden, lo que permitió una diferenciación con el resto de las naciones de América que iniciaban su proceso de independencia. La legalidad entregada por la élite comprendió que al poder solo se accede con un título jurídico previo, y ese título solo lo confieren las leyes. Al mismo tiempo, advirtió que por medio de la ley se administra la fuerza, de tal suerte que el binomio poder-fuerza fue clave para generar un cambio ordenado, lo que, como se revisó, duró al menos 60 años desde que se instauró el régimen portaliano.

Sin embargo, si se mira el asunto en clave jurídica, la ley de ese periodo (influida por el ideario codificador y exegeta), y cuya vigencia se adentra en el siglo XX, es artificial pues impide al juez -al resolver un caso particular- una interpretación de acuerdo con la realidad que, por esencia, es dinámica. Se optó por la seguridad antes que la justicia. Aquello corresponde a la característica más difundida y relevante de la codificación: la confianza exclusiva en el legislador como motor de cambio social, lo que no era equivalente a lo que comenzaba a ocurrir en la sociedad.

En este punto resulta pertinente la siguiente cita, que apunta a una cierta crítica hacia Andrés Bello. Explica Jocelyn-Holt:

\begin{abstract}
¿Qué es lo que se dice de Bello, en su máximo apogeo, opinión que se escuchaba incluso entre algunos de sus propios discípulos? Que en vez de persistir en la línea libertaria que marcaba la Independencia, se había ido imponiendo una enseñanza "clásica" en que predominaban "la forma, antes que el fondo mismo del pensamiento", el estudio del latín, del derecho romano y de los clásicos castellanos; un purismo del que se responsabiliza derechamente a Bello, y que estaría supuestamente obstaculizando la lucha contra el retraso oscurantista legado por España, el principal objetivo cultural postcolonial según los más avanzados. ${ }^{21}$
\end{abstract}

Las evidentes falencias del sistema de interpretación proveído por la exégesis con el inmovilismo del juez al aplicar la ley sin reconocerle un ámbito mínimo para el caso particular, el surgimiento de nuevos actores en el país con demandas sociales o reivindicativas de derechos para grupos, la dispersión e hipertrofia legislativa, la revitalización de la Constitución como norma jurídica, en especial en la protección de derechos fundamentales, la evolución de la ciencia jurídica, la creciente crítica a los órganos de representación que las crean, la vigencia de jurisdicciones supranacionales, entre otros, determinan como efecto una disconformidad progresiva sobre el rol de la ley, lo que hoy permite identificar la acentuada mutación en el sistema de fuentes formales

21 Jocelyn-Holt, El peso de la noche. Nuestra frágil fortaleza histórica, op. cit., p. 256. 
del derecho con la consiguiente infravaloración de la ley y la expansiva fuerza normativa de la Constitución, que será lo que se expondrá a continuación.

\section{La eficacia directa de la constitución}

La codificación del siglo XIX es un indicio concreto del legalismo que se desarrolla con especial fuerza en la ciencia jurídica del siglo XX.

El principio de legalidad en el Estado de derecho suponía, como señala Zagrebelsky, "la reducción del derecho a la ley y la exclusión, o por lo menos la sumisión a la ley, de todas las demás fuentes del derecho". ${ }^{22}$ Las leyes se justifican por la existencia de otra que las habilita, se privilegia el aspecto formal en su generación y aplicación, más que los aspectos sustantivos. Sobre las consecuencias se expone con claridad: “La II guerra mundial fue la demostración más palpable de que no podía aceptarse un Derecho por completo prescindente de valoraciones, pues, por mucho que la legislación antisemita del III Reich fuera aprobada por un gobierno elegido por una mayoría, claramente en él había ilegitimidad de contenido" ${ }^{23}$

A partir de aquellos lamentables sucesos, la ciencia jurídica tuvo que reformular y renovar su enfoque en torno a la ley, la constitución y la protección de los derechos fundamentales que se reforzó a nivel nacional y supranacional. En efecto, para la cultura jurídica moderna, la constitución deja de ser un conjunto de normas sobre organización y procedimientos de sus instituciones, para convertirse en un cuerpo normativo rematerializado, donde los derechos fundamentales sean "garantizados más allá de la voluntad de la mayoría y esa garantía solo puede ser operada con el recurso de la instancia jurisdiccional" ${ }^{24}$

Una consecuencia de ese cambio tiene relación con la producción y aplicación del derecho, el juez pétreo muta a otro donde cobra sentido la decisión judicial, la que se debe fundar en una norma superior, que normalmente será la constitución.

Es posible observar cómo, gradualmente, la ley se transforma: pasa de ser la primera fuente del derecho a perder influencia bajo la vigencia de esta constitución reforzada. Pérez-Royo dice sobre el particular:

Históricamente, la Constitución pertenecía al mundo de la política y no al del Derecho. Como norma jurídica, no jugaba ningún papel, de manera que la ley era so- 
berana. En el concepto moderno, la Constitución se introduce en el ordenamiento jurídico. Es en él una norma jurídica y una norma jurídica aplicable a través de un sistema de garantías y de la justicia constitucional. ${ }^{25}$

Como se aprecia, junto con definirse a la constitución como una norma jurídica directamente aplicable por los tribunales, surge otro antecedente relevante para el análisis: la ley es aplicada por los tribunales ordinarios, y su infracción determina la impugnación de las resoluciones específicas a través del recurso de casación en el fondo. ${ }^{26}$ Con las constituciones escritas, de modelos continentales, nacen en el siglo XX de manera progresiva los tribunales constitucionales, cuya misión es ejercer el control de constitucionalidad de las leyes, ${ }^{27}$ y para tal fin invalidan o abrogan del ordenamiento cualquier precepto legal que en la aplicación de un caso particular resulte contrario a la constitución. Para el cumplimiento de sus fines, la jurisdicción constitucional utiliza nuevos criterios de interpretación diversos de la interpretación de las leyes. Si del resultado de su análisis importa que el precepto legal afecta la constitución, deberá aplicar el principio lex superior o jerárquico con base en el principio de supremacía constitucional que reconocen expresamente tales cuerpos normativos.

Con la irrupción de la jurisdicción constitucional, la ley progresivamente comienza a perder su valor, su aplicación se torna incierta en caso de existir una eventual antinomia con la constitución. En tal sentido, Zagrebelsky expone:

La ley, un tiempo medida exclusiva de todas las cosas en el campo del derecho, cede así el paso a la Constitución y se convierte ella misma en objeto de medición. Es destronada en favor de una instancia más alta. Y esta instancia más alta asume ahora la importantísima función de mantener unidas y en paz sociedades divididas en su interior y concurrenciales. ${ }^{28}$

En efecto, en la actualidad, cualquier afectado podrá recurrir al Tribunal Constitucional, quien deberá aplicar la Constitución de manera directa y constatar la inaplicación o, en su caso, la inconstitucionalidad de la ley cuestionada. La Constitución es aplicable en virtud del sistema de eficacia directa y su fuerza

25 Javier Pérez-Royo, Las fuentes del derecho, 4 ed., Madrid, Tecnos, 1984, pp. 17-18.

26 "El recurso de casación, creado por la Revolución francesa, era un instrumento de defensa de la ley, entendiendo la ley en su sentido roussoniano y jacobino como voluntad general que constituye el valladar de defensa de los ciudadanos. La casación era un control de legalidad: un sistema de defensa de la ley, fuente singular del Derecho que acababa de alcanzar el cetro en el sistema de fuentes. La violación de la ley obligaba a considerar una sentencia y a romperla" (Luis Díez-Picazo, "Constitución, Ley y Juez", en Revista Española de Derecho Constitucional 15 (1985), pp. 9-23).

27 No obstante existir en el derecho comparado registro de control de constitucionalidad de leyes por los tribunales ordinarios (caso Marbury v. Madison de 1803), la situación en Chile fue distinta en el siglo XIX y hasta 1970, fecha en que se crea el Tribunal Constitucional. En efecto se dice: "durante la vigencia de la Carta de 1833, tanto la doctrina como la jurisprudencia estuvieron contestes en cuanto a que los tribunales carecían de atribuciones para declarar la inconstitucionalidad de las leyes. Así, el control político de las leyes era ejercido por el Congreso Nacional, siendo la modificación de las normas infra constitucionales la única forma de resguardar la supremacía" (Enrique Navarro, El control de constitucionalidad de leyes (1811-2011), Santiago, Cuadernos Tribunal Constitucional [2011], p. 15).

Zagrebelsky, El derecho dúctil. Ley, derechos, justicia, op. cit., p. 40. 
normativa irradia a las demás fuentes. ${ }^{29}$ La ley y el orden social que ella predicaba en su periodo inicial, se inhibe, se retrae. En suma, pierde el vigor que tenía en el orden portaliano y se aprecia un escaso poder de auctoritas en la ley. Hoy, en la defensa y aplicación de la Constitución es necesario destacar que el rol de los jueces ordinarios en Chile también cambia. Como se explicaba, en el modelo del Estado legal, los jueces eran considerados meros aplicadores de leyes, debían cumplir con el mandato del legislador con exclusión de cualquier voluntad discrecional. Un ejemplo palmario en dicha dimensión es citado por Baraona:

... en 1992 el presidente de la Corte Suprema don Enrique Correa Labra, ya fallecido, declaraba en un discurso inaugural del año judicial 1992, "la ley la dicta el poder político -Poder Legislativo y Poder Ejecutivo- y ellos dicen lo que es justo, sin que sea permitido al juez discutir o dudar de la justicia que la ley encierra". ${ }^{30}$

En la actualidad, con este nuevo escenario de fuentes formales, todos los derechos están unidos por normas constitucionales, no son meras declaraciones programáticas, por el contrario, gozarán de todos los recursos exigibles para su defensa. De igual manera, el método de interpretación se amplía, no existe la restricción de la exégesis para la protección de los derechos garantizados por la constitución.

En ese orden de ideas, cabe señalar que en el modelo chileno, la defensa y protección de los derechos fundamentales no solo es una atribución exclusiva del Tribunal Constitucional, sino que el mismo ordenamiento reconoce la existencia de acciones de competencia de los tribunales ordinarios, destinadas a resguardar la vigencia de la Constitución. En tal dimensión, corresponde mencionar a las acciones de protección (art. $20 \mathrm{CP}$ ) y amparo o habeas corpus (art. $21 \mathrm{CP}) .{ }^{31}$ En síntesis, la eficacia directa de la Constitución ha generado una consecuencia insospechada si se compara con el modelo anterior: una sostenida creación judicial de derechos al clamor de la defensa de la Constitución. Si

29 El sistema de eficacia directa significa que los jueces, y en general todos los llamados a aplicar el derecho, habrán de tomar la norma constitucional como una premisa de su decisión, igual que cualquier otra norma, con las siguientes consecuencias: a) dado que la constitución es norma superior habrán de examinar con ella todas las leyes y cualesquiera normas para comprobar si son o no conformes con la norma constitucional; $b$ ) habrán de aplicar la norma constitucional para extraer de ella la solución del litigio o, en general, para configurar de un modo u otro una situación jurídica; c) habrán de interpretar todo el ordenamiento conforme a la constitución. En otras palabras, si la constitución tiene eficacia directa no será solo norma sobre normas, sino norma aplicable, no será solo fuente sobre la producción, sino también fuente del derecho sin más (Ignacio de Otto, Derecho Constitucional. Sistema de fuentes, Madrid, Ariel, 2001, p. 76).

30 Baraona, "La cultura jurídica chilena: apuntes históricos, tendencias y desafíos", op. cit., p. 434.

31 Tales acciones son las clásicas o tradicionales que integran las llamadas facultades conservadoras de los tribunales, referidas a la protección de la constitución y los derechos fundamentales. Sin embargo, en la actualidad existe una tendencia del propio legislador a ampliar el catálogo de acciones protectoras de derechos fundamentales de competencia de los tribunales ordinarios en la República de Chile. A título ejemplar, se destacan las siguientes: acción por pérdida o desconocimiento de la nacionalidad (art. 12 CP), acción de indemnización por error judicial (art. 19, núm. 7, letra I CP). La ley también regula acciones frente la vulneración de derechos fundamentales: acción de amparo económico (Ley 18.971), acción que protege los datos de carácter personal o habeas data (Ley 19.628), acción de amparo ante el juez de garantías (art. 95 CPP), acción de no discriminación arbitraria (Ley 20.609). 
antes los tribunales ordinarios solo debían aplicar la ley, hoy para cumplir su cometido de resolver una contienda aplican todas las fuentes formales, lo que incluye a la Constitución por ser una norma jurídica directamente aplicable.

En este nuevo escenario, parece ser inevitable que la aplicación del derecho en la actualidad comporte cierto activismo judicial. Es sabido que la interpretación del derecho no es una actividad mecánica, que una vez expuestos los hechos, en este nuevo escenario los jueces ordinarios pueden invocar la Constitución para resolver un conflicto si se afecta un derecho fundamental. Un problema evidenciable es que la Constitución, como norma, contiene múltiples disposiciones, unas más amplias que otras, lo que implica que no tendrá con frecuencia contornos delimitados: la interpretación y la justificación, por tanto, son esenciales en este nuevo modelo, para reducir dosis de creación judicial $\mathrm{y}$, en consecuencia, la arbitrariedad judicial. Díez-Picazo, plantea este problema en los siguientes términos:

... junto con la extensión desorbitada de la técnica de aplicación directa de la Constitución están produciendo entre nosotros una potenciación extraordinaria del Derecho judicial $[\ldots]$

Llamo "Derecho judicial" a los pronunciamientos de los tribunales que no solo resuelven en justicia los casos concretos, sino que establecen reglas o doctrinas con una pretensión de sobrevivir a ese caso concreto y que carecen de una directa vinculación con la ley. Son por decirlo así, praeter legem y en algunos supuestos contra legem. ${ }^{32}$

Luego es posible preguntar ¿de qué manera las decisiones jurisdiccionales serán respetuosas y deferentes con la voluntad democráticamente expresada en leyes si los jueces pueden fundar sus argumentos en la Constitución? Si se respondiera de acuerdo con el pensamiento de Andrés Bello, la administración de justicia solo sería verdaderamente republicana y liberal cuando las leyes fuesen "puntual y escrupulosamente observadas". ${ }^{33}$ Hoy, que la ley está en permanente interinidad y en una posición de subordinación frente a la constitución, ¿cómo se cumplirían las exigencias de Bello al requerir a los jueces una mayor justificación de sus decisiones en un proceso que garantice a las partes un efectivo contradictorio, con lógica argumentativa y justificativa, lo que supone un resguardo sustancial del principio procesal de igualdad de partes, con exclusión de reglas formales o burocráticas de tutela de tal derecho? Como plantean Chaumet y Meroi, "es menester asumir una metodología que permita reconocer al razonamiento jurídico como intersubjetivo, dialógico y exigir a los jueces una mayor justificación de sus decisiones" ${ }^{34}$

\footnotetext{
32 Luis Díez-Picazo, "Constitución, Ley y Juez", op. cit., p. 22.

33 Víctor Tau, "Reforma y codificación en el pensamiento de Andrés Bello" (1830-1839), en AA.VV., Homenaje a don Andrés Bello, op. cit., p. 409.

34 Mario Chaumet y Andrea Meroi, “¿Es el derecho un juego de los jueces?”, en Boletín La Ley, (2008), en https:// www.academia.edu/15685828/_ES_EL_DERECHO_UN_JUEGO_DE_LOS_JUECES, fecha de consulta: 3 de mayo de 2019.
} 
Hasta acá se ha advertido de la llamada superación del valor tradicional de la ley por la prevalencia de la constitución como norma vinculante en desmedro de la misma ley, ¿es posible que se puedan identificar otros factores?

La respuesta es afirmativa. La superación de la mirada tradicional de la ley es un fenómeno complejo, que posee múltiples factores, uno de ellos consiste en reconocer la existencia de un quiebre de pensamiento. En efecto, la razón configurada desde la Ilustración, de acuerdo con criterios de abstracción, generalidad y objetividad es sustituida por lo concreto, lo empírico y lo subjetivo. De Cabo lo expone de la siguiente manera:

\begin{abstract}
A partir de estas consideraciones se entiende bien que un concepto de ley, con su carácter de "representación" general, de expresión de la voluntad e intereses globales y unitarios y máxima expresión de la voluntad e intereses globales y unitarios y máxima encarnación de la racionalidad y de la objetividad jurídico-estatal, esté fuera de la sintonía del momento cultural contemporáneo; de ahí que, por el contrario, conecten plenamente con ese momento procesos distintos como los de fragmentación jurídica y desformalización con progresiva pérdida de relevancia de los caracteres propios de las "fuentes formales" del Derecho estatal (supremacía o aplicación general), deslegalización y deterioro de la idea de código, así como la emergencia de determinados sujetos y grupos con la correspondiente erosión incluso del concepto de ordenamiento jurídico en cuanto estructura normativa también global y unitaria. ${ }^{35}$
\end{abstract}

El orden y la legitimidad que representaban la legalidad como concepto en los siglos XIX y XX, y que le dieron sentido histórico a la República, hoy son reemplazados por un periodo donde prevalece la deslegalización. Celloto y Conte identifican diversas causas que ameritan hablar de la superación de la ley: "En las últimas décadas, para responder a los impulsos múltiples, variados y sectoriales de una sociedad intrínsecamente diversificada y en impetuoso crecimiento, la regulación legislativa o, más en general, la regulación, resultó siempre más desordenada, abundante, $\mathrm{y}$, por tanto, excesiva". ${ }^{36}$

Las causas de la crisis de la ley generan otras consecuencias que contribuyen a admitir esta posición. En efecto, la pérdida de credibilidad en esta conlleva una fragmentación jurídica que se refleja, por ejemplo, en la existencia de estatutos especiales para grupos diversos que por distintas causas disponen de derechos subjetivos específicos diversos de los generales previsto por la ley común. Sobre la fragmentación jurídica en el ordenamiento procesal chileno, como motivo de la superación de la ley, es posible exponer y argumentar la siguiente situación: parado XXXIX (117) (2006), pp. 629-630. 
El artículo 14 del Código Civil chileno dispone que "la ley es obligatoria para todos los habitantes de la República, inclusos los extranjeros". Con prescindencia de la nacionalidad de la persona, es aplicable la ley nacional, sin distinción de ninguna clase. Las excepciones tradicionales a este principio son reconocidas por el derecho internacional y se refieren a la persona de un soberano extranjero, de los agentes diplomáticos y de las naves de guerra o tropas extranjeras en tránsito.

En la actualidad, sin embargo, es factible evidenciar un problema cuando surgen conflictos entre personas que pueden ser nacionales de un Estado y, aun así, se excluye de manera parcial la aplicación de la ley procesal nacional. ¿Es esto posible?

Obsérvese la existencia del fenómeno llamado multiculturalismo: culturas diferentes al interior de un Estado, que originan estatutos propios, disímiles del estatal, que usualmente corresponden al reconocimiento de derecho consuetudinario o ancestral, propio de pueblos originarios, tribales o grupos étnicos, cuya cultura es protegida por diversas normas, tanto nacionales como supranacionales, con aplicación directa por los propios Estados, los que normalmente surgieron con posterioridad a sus propias culturas y cosmovisiones, y que, de alguna manera, impusieron una identidad y prácticas ajenas a su tradición.

En tal perspectiva, es oportuno citar el Convenio 169 de la Organización Internacional del Trabajo (OIT), vigente en Chile desde 2009, que se aplica a los pueblos indígenas y tribales en países independientes, cuyas condiciones sociales, culturales y económicas los distingan de otros sectores de la colectividad nacional, y que estén regidos, total o parcialmente, por sus propias costumbres o tradiciones o por una legislación especial. Es el caso de los pueblos originarios de Chile. El Convenio señala que se aplica a quienes descienden de poblaciones que habitaban en el país o en una región geográfica a la que pertenecía el país en la época de la conquista o la colonización o del establecimiento de las actuales fronteras estatales.

El convenio insta a los Estados suscriptores para que tomen en cuenta sus costumbres, normas internas y tradiciones siempre que estas no sean incompatibles con los derechos fundamentales definidos por el sistema jurídico nacional ni con los derechos humanos internacionalmente reconocidos. ¿Cómo se enfoca la aplicación de la ley en la persona con el fenómeno del multiculturalismo? ¿Es posible en la resolución de un conflicto, una armonización del derecho estatal con el derecho consuetudinario propio de los pueblos originarios?

Es posible reconocer en el sistema procesal nacional la aplicación del derecho consuetudinario en la solución del conflicto por jueces estatales, ${ }^{37}$ sin embargo,

$37 \quad$ El artículo 19 de la Ley 20.066 (Ley de violencia intrafamiliar) establece de manera expresa la improcedencia de acuerdos de reparación en los casos de violencia intrafamiliar constitutivos de delitos en los términos que 
ello no está exento de tensiones. En efecto, la complejidad se presenta al juez cuando deba decidir la prevalencia del ordenamiento interno o, en su caso, aplicar el derecho ancestral, en caso de contradicción entre ambos estatutos. El Convenio 169 permite que los pueblos conserven sus costumbres e instituciones propias, siempre que estas no sean incompatibles con los derechos fundamentales definidos por el sistema jurídico nacional ni con los derechos humanos internacionalmente reconocidos. Un juez estatal, cuando deba decidir un conflicto, deberá observar como límites, además de la referida circunstancia, el orden público y los principios del Estado-nación. No obstante, en el proceso de aplicación del derecho pueden presentarse casos con criterios interpretativos diversos. De esa manera, se puede sugerir la existencia de una fragmentación al menos implícita del sistema jurídico, lo que permite dejar en evidencia que los criterios de unidad y racionalidad propios de la ley también se ven afectados en este nuevo modelo.

El ejemplo descrito permite dar cuenta que algunos de los atributos naturales de la ley son cuestionados. En tal dimensión, en forma adicional a la fragmentación, los valores de unidad y coherencia -propios del sistema legal- se rompen cada vez que el legislador tiene intención de sustraer determinados sujetos o grupos de sujetos al funcionamiento -a menudo ineficiente- de la ley general.

Por otra parte, frente a la siempre mayor complejidad de las relaciones sociales y económicas y, por tanto, de las situaciones jurídicas necesitadas de tutela jurisdiccional, el legislador actúa frecuentemente atrasado en decenios respecto al surgimiento de los problemas que debe afrontar. Ahora bien, si llegare a actuar a tiempo, la técnica legislativa -con una frecuencia mayor a lo esperable- adolece de defectos que generan contradicciones, como una compleja heterogeneidad normativa, lo que pulveriza su validez, por lo que el rol del juez adquiere mayor valor.

Finalmente, respecto a los factores referidos, se puede consignar la existencia de las jurisdicciones supranacionales, con misiones diferenciadas según el tipo de conflicto: i) protección de derechos fundamentales, por ejemplo, la Corte Interamericana de Derechos Humanos (Corte IDH); ii) cautelar ciertos bienes jurídicos esenciales para la convivencia a nivel global, como los delitos de lesa humanidad de competencia de la Corte Penal Internacional (CPI); iii)

prescribe la misma ley (art. 13 y ss.). Sin embargo, la Defensoría Penal Pública ha invocado el derecho consuetudinario de los pueblos originarios para resolver los conflictos con prevalencia de la ley nacional.

En tal contexto, las disculpas y un férreo compromiso de no repetir la agresión, sellado públicamente en su comunidad o ante las autoridades de esta (lonkos o machis), ha sido el medio validado, a través de acuerdos de reparación, por los juzgados de garantía de la Región de la Araucanía, para zanjar procedimientos por violencia intrafamiliar, cuando se han visto enfrentadas personas de la etnia mapuche. La Fiscalía es contraria a la aplicación de este criterio en la medida que es prohibido utilizar esta salida alternativa en procedimientos de violencia intrafamiliar. El Ministerio de la Mujer, por su parte, argumenta que existe otro tratado internacional sobre eliminación de todas las formas de discriminación hacia la mujer, por lo que el juez, para dirimir un caso, debe interpretar que la solución acogida no vulnere los derechos fundamentales de esta y la aplicación del estatuto propio del pueblo originario se armonice con la legislación interna. 
resolver conflictos de naturaleza mercantil o de inversiones entre particulares y los Estados, como el Centro Internacional de Arreglo de Diferencias Relativas a Inversiones (Ciadi). En todos los casos se facilita el acceso a tribunales extraestatales cuyas decisiones son plenamente eficaces y pronunciadas fuera del marco del principio de territorialidad, lo que transforma el concepto clásico de jurisdicción, y cambia el paradigma de una ley surgida al amparo del principio de la soberanía nacional que se aprecia nuevamente minimizado.

Estos factores, señalados en apretada síntesis, ¿afectan el sentido histórico del país sobre el valor de la ley en la cultura jurídica chilena de hoy? ¿Cómo adquiere valor la ley en la actualidad si el prestigio que esta poseía lo tiene la Constitución en la actualidad?

De ser una sociedad homogénea en el siglo XIX y parte del siglo XX, en la actualidad se está en presencia de una sociedad compleja, con nuevos actores y una pluralidad de demandas. Se aprecia la existencia de movilidad social y cambio político, y se incluyen nuevas fuerzas que representan la diversidad de ideas. En dicho proceso de modernización e institucionalización hubo inestabilidad, frustración social, pero también avances mayores o menores, que son reconocibles: urbanización, alfabetización, educación, acceso a la información, etc.

En tal dimensión, y pese a los certeros cuestionamientos expuestos sobre el valor o peso de la ley hoy, en Chile no se ha modificado la apreciación de la norma, radicada en la cultura jurídica interna. Para dar cuenta de lo anterior, es necesario señalar que el proceso legislativo y el principio de legalidad están institucionalizados en el país: se obedecen a pautas de conducta, las que son reiteradas, estables y apreciadas como parte de las cualidades que distinguen a la sociedad chilena como nación. Sin duda, la estabilidad del proceso no excluye plantear cuestionamientos, sugerir soluciones e implementar cambios para corregir los errores. Los factores de la superación de la ley no obstan a que esta se haya adaptado a los requerimientos de una sociedad compleja, aunque sea de manera imperfecta. En ese orden de ideas, todos los actores y partícipes en el sistema jurídico conocen que el parámetro de control en el ordenamiento lo entrega en la actualidad la Constitución, esto implica que la ley puede ser inaplicada o invalidada si afecta el principio de supremacía constitucional. Sin embargo, no es posible para una sociedad prescindir de ella, el principio de legalidad es fundamental para garantizar el Estado de derecho, por cuanto a través de la ley se controla el poder del Estado, se garantiza la libertad e igualdad y se proveen mecanismos que restringen actuaciones arbitrarias. La Constitución por sí sola no es capaz de hacer frente a esa empresa compleja y no exenta de dificultades.

En dicho orden de ideas, y para resaltar la vigencia del principio de legalidad, cabe señalar que al existir un conflicto que implique la intervención de un tribunal, para ejercer jurisdicción este deberá estar establecido con anterioridad 
a la perpetración del hecho, al igual que su competencia o atribuciones. Finalmente, el tribunal deberá asegurar que el procedimiento, también previsto por la ley, garantice que sea justo y racional, que supone imparcialidad, bilateralidad, exigencia de fundamentación de las sentencias, entre otras condiciones específicas. Con ello se advierte la importancia de la ley para materializar el acceso a la justicia y la solución de conflictos. Ninguna fuente suple a la ley en ese cometido y la constitución expresamente le entrega a esta la organización y las atribuciones de los tribunales.

De acuerdo con lo expuesto, aun cuando la ley se subordina a la constitución, esta garantiza el principio de reserva en favor de la ley para la regulación de determinados asuntos normativos, ello implica la prohibición de intervención de fuentes subordinadas, en particular aquellas que provienen de la potestad reglamentaria del presidente de la República y de los órganos del Estado. La existencia de la reserva de ley, conforme lo expresa Guastini, tiene dos funciones: a) una liberal o garantista, como tutela de los derechos fundamentales de los ciudadanos contra del poder ejecutivo, y b) otra democrática, lo que significa que determinados objetos o materias tendrán su origen en los órganos representativos donde también tienen voz las minorías políticas. ${ }^{38}$

La ley posee legitimación democrática, dado que su creación es un proceso deliberado de los órganos representativos, ello debe suponer que, por debajo de la constitución, la ley (y no los jueces) faciliten un disfrute general de los derechos y que sean garantizados efectivamente.

Sobre el valor de la ley, Laporta expone:

... parece necesario volver a recordar que el núcleo más importante y decisivo del ordenamiento jurídico debe estar integrado por un cuerpo coherente de leyes generales y abstractas a las que se ha de tributar una deferencia privilegiada, y que frente a esa exageración tan de moda de adscribirle todas las tareas normativas a la Constitución y a sus innumerables intérpretes, y de reclamar su presencia en todos y cada uno de los pequeños y grandes conflictos que se suscitan cotidianamente, es preciso hoy volver a reafirmar la confianza en el legislador y a plantearse con seriedad los términos de su reconstrucción y presencia. ${ }^{39}$

Uno de los desafíos de la ley en la actualidad es recuperar su coherencia y racionalidad, para ello se debe mejorar la técnica legislativa, es preciso reducir la hipertrofia de las leyes a fin de superar la idea del modelo del legislador en crisis, y neutralizar el activismo y la beatificación del juez como solución a dicha crisis. Con el fin de propender hacia ello, es necesario resguardar el principio del contradictorio, en todas las instancias y etapas jurisdiccionales. 
Es sugerente la idea de Aragón en el sentido de que no habría que detener el análisis en la desconfianza en la ley, sino que, por el contrario, en la excesiva confianza en la Constitución. En síntesis, señala que, si bien todo el ordenamiento se subordina e interpreta conforme a la Constitución, es improcedente que ciertos tipos de conflictos "como los problemas de arrendamientos urbanos, de operaciones bancarias, de disciplina urbanística, de contratación laboral, de seguridad social, de contratación administrativa, etc., hayan de resolverse aplicando la Constitución".${ }^{40}$ En efecto, la tarea para proyectar el sentido de nación en el futuro será la armonización de la Constitución con la ley, en el entendido de que ambas fuentes son esenciales para la vigencia de las instituciones de la República, y que proveen de sentido histórico a Chile.

\section{Reflexiones finales}

Se han analizado dos momentos sobre la ley: su apogeo y la superación de esta por la Constitución. Ambos han sido relevantes de estudiar, dado que la ley ha entregado un orden que ha proporcionado un sentido histórico a la República de Chile, aun cuando hoy sea rebasada por la Constitución. En efecto, el proceso legislativo está institucionalizado, posee etapas identificables y conocidas. De cualquier modo, a pesar de la infravaloración actual de la ley, la República de Chile se organiza como un ordenamiento de base legal. Ahora bien, si bien esta ya no es más la fuente suprema, permanece de cualquier forma en el centro del sistema de fuentes porque es fundamentalmente respecto de ella que puede determinarse la posición de todas las demás fuentes.

Aunque la ley en Chile haya sufrido evidentes cambios de posición jerárquica y el legislador esté sometido a palpables limitaciones, nada de ello nos obliga a abandonar el principio del imperio de la ley, dado que sin ley es muy difícil que exista Estado de derecho. A fin de evitar el activismo, la ley debe ser clara y coherente para que con ello se impida la aplicación de criterios personales, sociológicos o económicos ajenos a los estándares jurídicos que puedan significar una aparente promoción de la juridicidad para en definitiva removerla del ordenamiento.

\section{Referencias}

Álvarez, Ariel, Derecho y realidad. Notas de teoría sociológica, Rosario, Editorial Juris, 2005.

Amunátegui, Carlos, Teoría y fuentes del Derecho: Boni et Aequi, Santiago, Ediciones Universidad Católica de Chile, 2016.

$40 \quad$ Manuel Aragón Reyes, "El juez ordinario entre legalidad y constitucionalidad", en Anuario Facultad de Derecho Universidad Autónoma de Madrid 1 (1997), pp. 179-302. 
Aragón Reyes, Manuel, "El juez ordinario entre legalidad y constitucionalidad", en Anuario Facultad de Derecho Universidad Autónoma de Madrid 1 (1997), pp. 179-302, en http://afduam.es/wp-content/uploads/pdf/1/aragon_reyes.pdf

Araújo, Katya y Nelson Beyer, "Autoridad y autoritarismo en Chile. Reflexiones en torno al ideal-tipo portaliano", en Atenea 508 (2013), pp. 171-185. https://doi.org/10.4067/S0718-04622013000200012

Baraona, Jorge, "La cultura jurídica chilena: apuntes históricos, tendencias y desafíos", en Revista de Derecho P. Universidad Católica de Valparaíso XXXV (2010). https://doi.org/10.4067/S0718-68512010000200013

Celloto, Alfonso y Emmanuele Conte, "La ley. De los orígenes a la crisis", Boletín Mexicano de Derecho Comparado XXXIX (117) (2006), en https://revistas. juridicas.unam.mx/index.php/derecho-comparado/article/view/3891/4892

Chaumet, Mario y Andrea Meroi, “¿Es el derecho un juego de los jueces?", en Boletín La Ley, Buenos Aires, 2008, en https://www.academia. edu/15685828/_ES_EL_DERECHO_UN_JUEGO_DE_LOS_JUECES

De Cabo, Carlos, Sobre el concepto de ley, Madrid, Trotta, 2000.

De Otto Ignacio, Derecho Constitucional. Sistema de fuentes, Madrid, Ariel, 2001.

Díez-Picazo, Luis, “Constitución, Ley y Juez", en Revista Española de Derecho Constitucional 15 (1985), en http://www.cepc.gob.es/publicaciones/revistas/ revistaselectronicas? IDR=6\&IDN=317\&IDA $=24761$

Ducci, Carlos, Interpretación jurídica, 3 ed., Santiago, Editorial Jurídica de Chile, 1997.

Encina, Francisco, Resumen de la Historia de Chile, 9 ed., t. II, Santiago: Zigzag, 1972.

Ferrajoli, Luigi, Derechos y garantías. La ley del más débil, 2 ed., Madrid, Trotta, 2001.

Figueroa, María Angélica, "La codificación civil chilena y la estructuración de un sistema jurídico legalista", en AA.VV, Homenaje a don Andrés Bello, Santiago, Editorial Jurídica de Chile, 1982.

García-Huidobro, Cristóbal, Yo, Montt, Santiago, Editorial Vergara, 2009.

Guastini, Riccardo, Las fuentes del derecho: fundamentos teóricos, 2 ed., Lima, Ediciones Legales EIRL, trad. César Moreno, 2017.

Guzmán Brito, Alejandro, "La codificación del Derecho", en Revista Derecho P. Universidad Católica de Valparaíso 8 (1984), en http://www.rdpucv.cl/index. $\mathrm{php} / \mathrm{rderecho/article/viewArticle/115}$ 
Heise, Julio, 150 años de evolución institucional, 7 ed., Santiago, Editorial Andrés Bello, 1990.

Jocelyn-Holt, Alfredo, El peso de la noche. Nuestra frágil fortaleza histórica, Buenos Aires, Ariel, 2014.

Laporta, Francisco J., El imperio de la ley. Una visión actual, Madrid, Trotta, 2007.

Navarro, Enrique, El control de constitucionalidad de leyes (1811-2011), Santiago, Cuadernos Tribunal Constitucional, 2011.

Núñez, José Ignacio, Neoconstitucionalismo y control de constitucionalidad de la ley: ¿el constitucionalismo del derecho libre?, México, Porrúa, 2013.

Palma, Eric, La constitucionalización del proceso penal en Chile y sus alcances en la doctrina y práctica procesal del siglo XIX, Santiago, Colección de Investigaciones Jurídicas, Universidad Alberto Hurtado, 2004.

Pérez-Royo, Javier, Las Fuentes del Derecho, 4 ed., Madrid, Tecnos, 1984.

Tau, Víctor, "Reforma y codificación en el pensamiento de Andrés Bello (18301839)", en AA.VV, Homenaje a don Andrés Bello, Santiago, Editorial Jurídica de Chile, 1982.

Zagrebelsky, Gustavo. El Derecho dúctil. Ley, derechos, justicia, 11 ed., Madrid, Trotta, trad. Marina Gascón, 2011. 